\title{
Relation between grades of acquired nasopharyngeal stenosis and severity of obstructive sleep apnea symptoms
}

\author{
Mohammad Waheed El-Anwar, Ehsan Hendawy ${ }^{*}$ and Mohamed Eesa
}

\begin{abstract}
Background: Nasopharyngeal stenosis (NPS) is a rare condition defined as the obstruction of the communication between the oropharynx and nasopharynx owing to scar contracture of the soft palate, tonsillar pillars, and posterior pharyngeal wall. NPS could be primary (attributed to a disease process such as rhinoscleroma) or secondary caused by prior surgery. In this study, we discuss the clinical manifestation of the acquired nasopharyngeal stenosis (NPS) and to investigate if there is a relation between the grade of the acquired NPS and the severity of obstructive sleep apnea (OSA) and patients' symptoms. So, this cross-sectional study was conducted on patients who had post-surgical NPS of different grades. Then, the severity of snoring \pm OSA and VAS of symptoms in those patients was assessed in different grades of the NPS, and the results were also statistically compared.

Results: Within the included 22 patients, there were no statistical differences between grade 1 and in grade 2 as regards age $(p=0.0619)$ or sex $(p=0.21137)$. The mean AHI was significantly more $(p=0.004)$ in grade 2 NPS than grade 1 NPS. The VAS of difficult nasal breathing and dysphagia were significantly worse $(p<0.0001)$ in grade 2 NPS than in grade 1 , while the VAS of snoring did not differ significantly $(p=0.3466)$ between grade 1 and grade 2 NPS.

Conclusion: Grade 2 NPS leads to significantly more severe AHI, dysphagia, and difficult nasal breathing than grade 1 NPS. But the difference in the grade of NPS did not cause differences in the snoring intensity.

Keywords: Nasopharyngeal stenosis, Obstructive sleep apnea, Snoring, Apnea-hypopnea index, Dysphagia, UPPP, Pharynx
\end{abstract}

\section{Background}

Nasopharyngeal stenosis (NPS) is a rare condition defined as the obstruction of the communication between the oropharynx and nasopharynx owing to scar contracture of the soft palate, tonsillar pillars, and posterior pharyngeal wall. NPS could be primary (attributed to disease process such as rhinoscleroma) or secondary NPS that caused by prior surgery (postoperative NPS). Nowadays, most NPS cases are commonly secondary to uvulopalatopharyngoplasty

* Correspondence: ehsanhendawy@gmail.com

University of Zagazig, Department of Otorhinolaryngology, Head-Neck Surgery, Zagazig 44511, Egypt

\section{Springer Open}

(UPPP), adenotonsillectomy, laser-assisted uvulopalatoplasty (LAUP), or radiotherapy for nasopharyngeal carcinoma $[1,2]$. However, some cases of NPS were reported after severe erosive oral lichen planus [3], secondary to extra-laryngeal tuberculosis [4], and without known etiology was reported [5]. NPS is graded as type I (mild) when the lateral aspects of the soft palate adhere to the posterior pharyngeal wall. Type II (moderate) showed circumferential scarring with a small central opening $(1-2 \mathrm{~cm}$ in diameter) of the soft palate [6]. Type III (severe) showed fusion of the entire soft palate with the

(c) The Author(s). 2021 Open Access This article is licensed under a Creative Commons Attribution 4.0 International License, which permits use, sharing, adaptation, distribution and reproduction in any medium or format, as long as you give appropriate credit to the original author(s) and the source, provide a link to the Creative Commons licence, and indicate if changes were made. The images or other third party material in this article are included in the article's Creative Commons licence, unless indicated otherwise in a credit line to the material. If material is not included in the article's Creative Commons licence and your intended use is not permitted by statutory regulation or exceeds the permitted use, you will need to obtain permission directly from the copyright holder. To view a copy of this licence, visit http://creativecommons.org/licenses/by/4.0/. 
posterior and lateral pharyngeal walls, leaving a remaining opening $<1 \mathrm{~cm}$ [6]. Patients with NPS usually manifest with nasal obstruction, dysphagia, snoring, and obstructive sleep apnea (OSA) [7, 8]. The ideal treatment of NPS is by preventing it using careful surgical technique, judicious use of electrocautery, avoidance of leaving opposing bared mucosal surfaces, and avoidance of excessive mucosal resections. Thus, nowadays, UPPP is mostly replaced by expansion pharyngoplasty and suspension sutures [9-12]. Definitive treatment is often very difficult and may lead to more scarring and restenosis. With increasing electro-cautery use and different palatal surgery techniques, the incidence of NPS as well increases [6]. However, not much has been written about this challenging NPS, and the standardized description had not yet been presented [13, 14] with no previous description of the relation between the severity of NPS and the severity of the patients' manifestations.

The aim of the current study was to present and discuss the clinical manifestation of the acquired NPS and to investigate if there is a relation between the grade of the acquired NPS and the severity of OSA and other patients' symptoms.

\section{Methods}

\section{Study design}

This cross-sectional study was conducted at the Otolaryngology, Head and Neck Surgery Department, starting from April 2016 until April 2020 including patients who complained of manifestations including snoring \pm OSA due to acquired postsurgical NPS.

NPS was assessed via the upper airway fiberoptic nasoendoscopy and oral cavity examination, and then the NPS was graded into 3 grades:

Grade I: there is minimal scar tissue lead to just adherence between lateral aspects of the soft palate and the posterior pharyngeal wall without lengthening of the soft palate.

Grade II: there is excessive scar tissue with lengthening of soft palate leaving a small opening in the soft palate with 1 to $2 \mathrm{~cm}$ diameter.

Grade III: there is a complete fusion of soft palate and tonsillar pillars with posterior pharyngeal wall atresia or stenosis leaving a pinpoint hole less than $1 \mathrm{~cm}$ in diameter.

Patients with significant craniofacial anomalies disturbing the upper airway and patients who had retrolingual and/or laryngeal collapse were excluded.
All cases underwent complete history taking, full ENT examination, awake fiberoptic nasoendoscopy, and polygraphy.

\section{Ethics and consent to participate}

This work was conducted in agreement to the declaration of Helsinki on Biomedical Research Involving Human Subjects, and University IRB approved the study proposal (IRB 2016-2-2016). A prior written informed consent was obtained from the study participants and the patients' privacy was protected.

\section{Outcome measures}

1- Subjective assessment of the NPS by the upper airways endoscopy and oral cavity exploration.

2- Visual analog scale (VAS 0-10) for the assessment of snoring, difficult nasal breathing, and dysphagia (0 "no complaint" to 10 "severe complaint").

3- Polygraphy was performed to determine the apneahypopnea index (AHI).

\section{Statistical analysis}

Results were statistically compared via tests from the SPSS program version 20 (Chicago, IL, USA). $T$ test was used to compare between quantitative data while chisquare $\left(\chi^{2}\right)$ test was utilized to compare between qualitative records. The $P$ value was considered significant if it is $<0.05$.

\section{Results}

Within the studied 22 patients, there were 17 males (77.3\%) and 5 females (22.7\%). Their mean age was $46.7 \pm 5.9$ years $($ range $=38-56$ ). Nineteen NPS patients (86.4) were caused by uvulopalatopharyngoplasty (UPPP) while the remaining three patients (13.6\%) were caused by adenotonsillectomy. All patients had OSA that was documented by polygraphy with AHI ranged between 5.5 and 38.8 (Table 1): 3 severe, 13 moderate, and 6 mild OSA.

Table 1 Data of the included patients

\begin{tabular}{lll}
\hline Age & Range & $38-56$ years \\
& Mean \pm SD & $46.7 \pm 5.9$ \\
Sex & Males & $17(77.3 \%)$ \\
Cause of stenosis & Females & $5(22.7 \%)$ \\
& UPPP & $19(86.4 \%)$ \\
Grade of stenosis & Adenotonsillectomy & $3(13.6 \%)$ \\
& Grade 1 & $8(36.4 \%)$ \\
AHI & Grade 2 & $14(63.6 \%)$ \\
\hline
\end{tabular}


Grade 1 NPS was detected in 8 patients (22.2\%): 5 males and 3 females with a mean age of $43.6 \pm 4.7$ years (range $=38-53$ ), while grade 2 was reported in 14 patients: 12 males and 2 females with a mean age of $48.4 \pm$ 7.93 years (range $=41-56$ ). There were no statistical differences between patients in grade 1 and in grade 2 as regards age $(p=0.0619)$ or sex $(p=0.21137)$ (Table 2).

On the other hands, the mean AHI was significantly more $(p=0.004)$ in grade 2 NPS (mean $=26.6 \pm 7.93$, range $=12-36.8)$ than grade 1 NPS $($ mean $=12.6 \pm 6.6$, range $=5.5-20$ ).

Grade 1 stenosis showed 4 mild OSA and 4 moderated OSA, while grade 2 NPS showed 2 mild OSA, 9 moderate OSA, and 3 severe OSA.

As regard the VAS of symptoms, difficult nasal breathing was significantly worse $(p<0.0001)$ in grade 2 NPS $($ mean $=7.14 \pm 0.6)$ than grade $1($ mean $=5.5 \pm 0.5)$. Dysphagia was also significantly more severe $(p<$ 0.0001 ) in grade 2 NPS (mean VAS $=3.86 \pm 0.6$ ) than grade 1 NPS (mean VAS $=2.5 \pm 0.5$ ), while the VAS of snoring did not differ significantly $(p=0.3466)$ between grade 1 NPS (mean $=6 \pm 1$ ) and grade 2 NPS (mean = $6.4 \pm 0.9)$ (Table 2).

\section{Discussion}

Nasopharyngeal stenosis is a serious problem that represents one of the challenging problems that can complicate palatal surgeries. But because it is not a common condition, it was not well described in the literature. At the same time, not much has been written about this severe complication [15].

Up to the best of our knowledge, there is no previous study that investigated the relation between different severity (grades) of the NPS and the patient symptoms and the OSA severity.

In the current study, males were more affected than females. Similarly, the two studied cases by Toh et al. [16] and the three cases repaired by Magdy et al. [13] were males. However, from the results of the current study, age and sex did not significantly affect the severity (grade) of the NPS $(p>0.05)$.
In accordance to the results of Madgy et al. [13], most cases of acquired NPS arise after UPPP in the current study (86.4\%). Thus, NPS is a major complication of UPPP [17] reflecting the importance of replacing the UPPP by less invasive mucosa preserving recent surgical procedures for the treatment of OSA such as expansion pharyngoplasty and suspension sutures [9-12].

In the current study, 3 cases of the included NPS were caused by adenotonsillectomy. This could be attributed to some risk factors such as excessive mucosal removal, keloid tendency, existence of concomitant nasopharyngeal inflammation, and an extreme surgical electrocautery use [18].

In the current study, we used the subjective VAS of symptoms to assess the patients' manifestations and we objectively evaluated OSA by polygraphy to precisely confirm the diagnosis and severity of OSA calculating the AHI. Then, we investigated the correlations of obtained data to the severity (grades) of the NPS.

Severe cases of NPS (grade 3) were not detected in the current study because they are much far less encountered than other grades $[16,18]$.

OSA was objectively documented in all NPS cases in our study even in mild NPS, and it was clearly found that more severe stenosis (grade 2) leads to more severe OSA than mild stenosis (grade 1$)(p=0.004)$. In addition, VAS of nasal obstruction and dysphagia was found also to be more severe in grade 2 stenosis than grade $1(p<0.0001)$. This reflects the importance and reliability of the used NPS grading in predicting the OSA severity and the importance to try to treat the NPS, particularly with more stenosis as grade 2 . Due to the high recurrence rates noted in the NPS management, many treatment modalities are now available. The surgical options reported in literature include the usage of either soft palate or pharyngeal wall flaps $[15,16,18-20]$ after excision of the scarred tissue. But, the NPS is prone to high recurrence incidence in spite of adequate planning and proper techniques [18].

However, it was noticeable that the snoring score did not differ significantly between different grades of the NPS $(p=0.3466)$ that could be attributed to the excess

Table 2 Differences between grade 1 and grade 2 stenosis

\begin{tabular}{lllll}
\hline & Grade 1 & Grade 2 & Test & X \\
\hline Sex & & & & \\
$\quad$ Male & 5 & 12 & & \\
$\quad$ Female & 3 & 2 & & \\
Age (years) & $43.6 \pm 4.7$ & $48.4 \pm 21137, \mathrm{NS}$ \\
Mean AHI & $12.6 \pm 6.6$ & $26 . \pm 7.93$ & $t=1.9781$ & $0.0619, \mathrm{NS}$ \\
Difficult nasal breathing & $5.5 \pm 0.5$ & $7.14 \pm 0.6$ & $t=4.2166$ & $0.004, \mathrm{~S}$ \\
Snoring & $6 \pm 1$ & $6.4 \pm 0.9$ & $t=6.5261$ & $<0.0001, \mathrm{~S}$ \\
Dysphagia & $2.5 \pm 0.5$ & $3.86 \pm 0.6$ & $t=0.964$ & $0.3466, \mathrm{NS}$ \\
\hline
\end{tabular}

AHI apnea-hypopnea index, NS non-significant, $S$ significant 
scar tissues formation and stiffing of the soft palate and pharyngeal walls that greatly limit their vibration even with more severe obstruction in the velopharyngeal area. This is important to be known by the doctors and the patients, particularly during counseling.

The repair of NPS is difficult because this is an uncommon clinical entity. The success of surgical correction of traumatic NPS has been based mostly on the subjective relief of the pre-operative symptoms [16].

But in the current study, we used the subjective VAS of symptoms and grading of stenosis and the objective evaluation OSA by polygraphy to precisely measure the AHI evaluation.

Because the first step for the appropriate dealing with the NPS is the good description of the NPS, the current study puts a base for a detailed description of NPS patients' manifestations and accurately confirms the diagnosis and severity of OSA in those NPS patients in relations to the severity (grades) of the NPS. But, further studies on the effect of different surgical procedures for repair of the NPS is still required

\section{Conclusion}

Grading of the NPS can indicate the severity of the OSA, nasal obstruction, and dysphagia. But snoring was not significantly affected by NPS grades. This should be considered during patient counseling before surgical repair.

\section{Abbreviations}

AHI: Apnea-hypopnea index; LAUP: Laser-assisted uvulopalatoplasty; NPS: Nasopharyngeal stenosis; OSA: Obstructive sleep apnea; UPPP: Uvulopalatopharyngoplasty; VAS: Visual analog scale

\section{Acknowledgements}

Not applicable

\section{Consent for personal data of the manuscript}

Not applicable (no images or videos related to participants).

\section{Authors' contributions}

MWE suggested and modified the idea, reviewed literature, designed the study and concept, did statistical analysis, interpreted the data, wrote and revised the article, and approved the final manuscript to be published; ME collected the data, analyzed the data, revised the article, and contributed to the final approval of the article; EH reviewed the literature, collected and tabulated the data, and contributed to the data interpretation, critical revision of the manuscript for important intellectual content, and final approval of the article. All authors have read and approved the manuscript.

\section{Funding}

None; the authors declare no financial support or interest to this study.

\section{Availability of data and materials}

The datasets used and/or analyzed during the current study are available from the corresponding author on reasonable request.
Ethics approval and consent to participate

A written informed consent was obtained from the study participants, and Zagazig University IRB approved the study proposal (IRB 2016-2-2016).

Consent for publication

Not applicable.

Received: 21 August 2020 Accepted: 20 January 2021

Published online: 05 February 2021

References

1. Giannoni C, Sulek M, Friedman EM, Duncan NO III (1998) Acquired nasopharyngeal stenosis: a warning and review. Arch Otolaryngol Head Neck Surg 24:163-167

2. Mclaughlin KE, Jacobs LN, Todd NW (1977) Management of nasopharyngeal stenosis in children. Laryngoscope 107(10):1322-1331

3. Henry A, Biddlestone J, McCaul J (2019) 'Nasal flossing': a case report of nasopharyngeal stenosis due to severe erosive lichen planus and a novel therapeutic intervention. Int J Surg Case Rep 54:99-102

4. Cranford J, Kadakia S, Berzofsky C (2016) Palatopharyngoplasty for treatment of nasopharyngeal stenosis secondary to extra-laryngeal tuberculosis. Am J Otolaryngol 37(6):559-562

5. Korkmaz H, Selcuk OT, Tatar EC, Saylam G, Ozdek A (2012) Complete nasopharyngeal stenosis: presentation of a rare case. EAJM 44:185-187

6. Krespi YP, Kacker A (2002) Management of nasopharyngeal stenosis following uvulopalatoplasty. Oper Tech Otolaryngol Head Neck Surg 13(2): 161-165

7. Mackenty J (1927) Nasopharyngeal atresia. Arch Otolaryngol 6:1-27

8. Bennhoff D (1979) Current management of nasopharyngeal stenosis: indications for Zplasty. Laryngoscope 89:1585-1592

9. Sorrenti G, Piccin O (2013) Functional expansion pharyngoplasty in the treatment of obstructive sleep apnea. Laryngoscope 123:2905-2908

10. El-Ahl MA, El-Anwar MW (2016) Expansion pharyngoplasty by new simple suspension sutures without tonsillectomy. Otolaryngol Head Neck Surg 155(6):1065-1068

11. Askar SM, El-Anwar MW (2018) Double suspension sutures: a simple surgical technique for selected cases of obstructive sleep apnea: our experience with twenty-two patients. Clin Otolaryngol 43(2):753-757

12. Askar SM, El-Anwar MW, Awad A (2018) Modified anterior palatoplasty and double suspension sutures (with or without tonsillectomy) in selected patients with obstructive sleep apnea: a preliminary report. Sleep Breath 22(3):789-795

13. Madgy DN, Walter Belenky W, Dunkley B, Shinhar S (2005) A simple surgical technique using the plasma hook for correcting acquired nasopharyngeal stenosis. Laryngoscope 115:370-372

14. Eppley BL, Sadove AM, Hennon D, van Aalst JA (2006) Treatment of nasopharyngeal stenosis by prosthetic hollow stents: clinical experience in eight patients. Cleft Palate Craniofac J 43(3):374-378

15. Kresp YP, Kacker A (2016) Management of nasopharyngeal stenosis after uvulopalatoplasty. Otolaryngol Head Neck Surg 123(6):692-695

16. Toh E, Pearl AW, Genden EM, Lawson W, Urken ML, Bivalved (2004) Palatal transposition flaps for the correction of acquired nasopharyngeal stenosis. Am J Rhinol 14:199-204

17. Smith ME (2005) Prevention and treatment of nasopharyngeal stenosis. Oper Tech Otolaryngol Head Neck Surg 16(4):242-247

18. Cammaroto G, Stringa LM, Cerritelli L, Bianchi G, Meccariello G, Gobbi R, lannella G, Magliulo G, Zhang H, Baghat AY, Galletti F, Pelucchi S, Stomeo F, Younes MB, AlAjmi M, De Vito A, Vicini C (2020) Acquired nasopharyngeal stenosis correction using a modified palatal flaps technique in obstructive sleep apnea (Osa) patients. Int J Environ Res Public Health 17:2048

19. Abdel-Fattah G (2012) Palatal eversion: a new technique in treatment of nasopharyngeal stenosis. Int J Pediatr Otorhinolaryngol 76(6):879-882

20. Nangole FM, Khainga SO (2014) FAMM flap in reconstructing postsurgical nasopharyngeal airway stenosis. Plastic Surgery Int 2014(276058):1-6

\section{Publisher's Note}

Springer Nature remains neutral with regard to jurisdictional claims in published maps and institutional affiliations. 